\title{
Reporting and Interpreting Working Memory Performance in $n$-back Tasks
}

\author{
Adrian Meule ${ }^{1,2 *}$ \\ ${ }^{1}$ Department of Psychology, University of Salzburg, Salzburg, Austria, ${ }^{2}$ Center for Cognitive Neuroscience, University of \\ Salzburg, Salzburg, Austria
}

Keywords: working memory, $n$-back task, emotional stimuli, reaction times, accuracy

Working memory is an executive function, which involves holding information in mind and mentally working with it (Diamond, 2013). A widely used measure for the assessment of working memory function is the $n$-back task (Owen et al., 2005). Here, participants are typically instructed to monitor a series of stimuli and to respond whenever a stimulus is presented that is the same as the one presented $n$ trials previously. Common versions are 2-back and 3-back tasks, in which participants have to respond to stimuli that have been presented two or three trials earlier. Zero-back and 1-back versions are also often used as control conditions.

In most studies, participants are required to respond with a button press to the relevant stimuli (= targets) and to withhold responses to distractor stimuli (= non-targets). Yet, there are also studies, in which participants are required to indicate for each trial whether the stimulus represents a target or a non-target (e.g., by pressing two different buttons; Jonides et al., 1997; Carlson et al., 1998; Perlstein et al., 2003; Harvey et al., 2005; Miller et al., 2009). Stimuli in classical $n$-back tasks are numbers or words, but pictorial versions, which display, for example, emotional scenes (Marx et al., 2011; Hur et al., in press), faces (Cromheeke and Mueller, 2016), or food (Meule et al., 2012; Meule, 2016) have also been used in recent years.

As dependent variables, most studies report response latencies (= reaction times) and accuracy (in \%) or the number of errors. With increasing task difficulty (i.e., with increasing ns), reaction times usually increase and accuracy decreases (e.g., Jonides et al., 1997; Carlson et al., 1998; Perlstein et al., 2003; Harvey et al., 2005; Miller et al., 2009; Schmidt et al., 2009). Similarly, reaction times and accuracy are usually negatively correlated (e.g., Carter et al., 1998). In other words, higher reaction times are associated with a higher number of errors. Although this relationship exists, it appears that reaction times and accuracy have dissociable correlates. For example, Jaeggi et al. (2010) examined various $n$-back tasks and found several dissociations between reaction times and accuracy. For instance, higher accuracy (but not reaction times) in visuospatial, auditory, and dual 3-back tasks was correlated with higher fluid intelligence as measured with the Raven test. In visuospatial $n$-back tasks, reaction times (but not accuracy) were associated with reading span and digit span forward performance.

In addition to these findings, a recent study by Hur et al. (in press) further highlights the role of reaction times vs. accuracy. In that study, pictures of emotional scenes were used in a 0-back task (labeled as perception task) and a 2-back task (labeled as working memory task). The authors argued that there was a ceiling effect in accuracy and more meaningful variation in reaction times in the perception task and, thus, they focused on interpreting reaction time results. In the working memory task, however, there was more variability in accuracy and less variability in reaction times and, thus, they focused on interpreting accuracy results because "participants' efforts are generally focused more on performing the task accurately than responding as fast as they can" (p. 4).

In light of these findings, how is interpretation of results affected when associations for some $n$-back task performance indices can be found but not for others? For example, in two studies that either used emotional words (Kopf et al., 2013) or pictures of emotional scenes (Marx et al., 2011) it was found that accuracy (but not reaction times) differed as a function of emotional

Received: 05 February 2017 Accepted: 23 February 2017 Published: 07 March 2017

Citation:

Meule A (2017) Reporting and Interpreting Working Memory Performance in $n$-back Tasks.

Front. Psychol. 8:352

doi: 10.3389/fpsyg.2017.00352 
valence of the stimuli. In contrast, effects of emotional stimuli (here: faces) were only found for reaction times and not for accuracy in a recent study by Cromheeke and Mueller (2016). Yet, the authors concluded that "allocating attention to affective information improved working memory" (p. 295). It might be argued that it is at least debatable if emotional stimuli indeed affected working memory performance as participants' ability to discriminate between targets and non-targets was not influenced. What these examples illustrate is that reaction times and accuracy in $n$-back tasks should not be interpreted interchangeably. Specifically, I argue that it is not reasonable when different studies reach similar conclusions (e.g., that effects of certain stimuli on or certain group differences in working memory performance were found), although these conclusions are based on different dependent variables (e.g., on reaction times in one study and on accuracy in another study).

In addition to these considerations, what constitutes accuracy is surprisingly rarely defined in most reports and/or it includes different types of errors (e.g., Jonides et al., 1997; Carlson et al., 1998; Perlstein et al., 2003; Harvey et al., 2005; Miller et al., 2009; Dodds et al., 2011). In $n$-back tasks, participants can either correctly press a button in response to targets $(=$ hits), incorrectly press a button in response to non-targets (= commission errors or false alarms), and incorrectly do not press a button in response to targets $(=$ omission errors or misses). However, researchers often do not make this distinction (for an exception see, e.g., Schmidt et al., 2009). In contrast to motor inhibition tasks (e.g., Go/No-go tasks), in which the main measure of interest is commission errors (e.g., Newman et al., 1985), omission errors are more frequent than commission errors in $n$-back tasks. Of note, it appears that these two types of errors have different correlates and, thus, may represent different processes. For example, in two studies that used 2back tasks with food and neutral pictures (Meule et al., 2012; Meule, 2016), reaction times were positively correlated with the number of omission errors $\left[r_{(n=70)}=0.440, p<0.001\right.$

\section{REFERENCES}

Carlson, S., Martinkauppi, S., Rämä, P., Salli, E., Korvenoja, A., and Aronen, H. J. (1998). Distribution of cortical activation during visuospatial n-back tasks as revealed by functional magnetic resonance imaging. Cereb. Cortex 8, 743-752. doi: $10.1093 /$ cercor/8.8.743

Carter, C. S., Perlstein, W., Ganguli, R., Brar, J., Mintun, M., and Cohen, J. D. (1998). Functional hypofrontality and working memory dysfunction in schizophrenia. Am. J. Psychiatry 155, 1285-1287. doi: 10.1176/ajp.155.9.1285

Cromheeke, S., and Mueller, S. C. (2016). The power of a smile: stronger working memory effects for happy faces in adolescents compared to adults. Cogn. Emot 30, 288-301. doi: 10.1080/02699931.2014.997196

Diamond, A. (2013). Executive functions. Annu. Rev. Psychol. 64, 135-168. doi: 10.1146/annurev-psych-113011-143750

Dodds, C. M., Bullmore, E. T., Henson, R. N., Christensen, S., Miller, S., Smith, M., et al. (2011). Effects of donepezil on cognitive performance after sleep deprivation. Hum. Psychopharmacol. Clin. Exp. 26, 578-587. doi: 10.1002/ hup. 1248

Haatveit, B. C., Sundet, K., Hugdahl, K., Ueland, T., Melle, I., and Andreassen, O. A. (2010). The validity of d prime as a working memory index: results from the "Bergen n-back task." J. Clin. Exp. Neuropsychol. 32, 871-880. doi: 10.1080/13803391003596421 and $\left.r_{(n=56)}=0.449, p=0.001\right]$, but not with the number of commission errors $\left[r_{(n=70)}=0.095, p=0.435\right.$ and $r_{(n=56)}$ $=0.178, p=0.188]$. Omission and commission errors were unrelated $\left[r_{(n=70)}=0.093, p=0.443\right.$ and $r_{(n=56)}=0.145, p=$ 0.285 ]. Moreover, in a study by Oberauer (2005), in which neutral words were used, only omission but not commission errors or reaction times were associated with measures of working memory capacity.

In conclusion, it is argued that researchers need to carefully interpret their findings derived from $n$-back tasks, particularly when these findings diverge depending on whether using reaction times or accuracy. Moreover, it appears necessary that researchers not only report accuracy but also differentiate between omission and commission errors. In addition, it may be preferable to report other task performance indices that are calculated from hits and false alarms such as discrimination index $d^{\prime}$ and response bias $C$, as has been suggested by researchers who used modified versions of the $n$-back task (Kane et al., 2007; Haatveit et al., 2010). As the $n$-back task has been criticized for lacking clear associations with other working memory tasks (Kane et al., 2007; Jaeggi et al., 2010), using more fine-grained analyses of $n$-back task performance beyond reporting reaction times and accuracy may, therefore, reveal clearer insights about its validity as a measure of working memory performance, its neural or psychopathological correlates, and its utility in applied neuropsychology.

\section{AUTHOR CONTRIBUTIONS}

The author confirms being the sole contributor of this work and approved it for publication.

\section{ACKNOWLEDGMENTS}

Publication of this article was supported by the Open Access Publication Fund of the University of Salzburg.

Harvey, P. O., Fossati, P., Pochon, J. B., Levy, R., LeBastard, G., Lehéricy, S., et al. (2005). Cognitive control and brain resources in major depression: an fMRI study using the n-back task. Neuroimage 26, 860-869. doi: 10.1016/j.neuroimage.2005.02.048

Hur, J., Iordan, A. D., Dolcos, F., and Berenbaum, H. (in press). Emotional influences on perception and working memory. Cogn. Emot. doi: 10.1080/02699931.2016.1213703

Jaeggi, S. M., Buschkuehl, M., Perrig, W. J., and Meier, B. (2010). The concurrent validity of the N-back task as a working memory measure. Memory 18, 394-412. doi: 10.1080/09658211003702171

Jonides, J., Schumacher, E. H., Smith, E. E., Lauber, E. J., Awh, E., Minoshima, S., et al. (1997). Verbal working memory load affects regional brain activation as measured by PET. J. Cogn. Neurosci. 9, 462-475. doi: 10.1162/jocn.1997.9.4.462

Kane, M. J., Conway, A. R., Miura, T. K., and Colflesh, G. J. (2007). Working memory, attention control, and the N-back task: a question of construct validity. J. Exp. Psychol. Learn. Mem. Cogn. 33, 615-622. doi: 10.1037/0278-7393.33.3.615

Kopf, J., Dresler, T., Reicherts, P., Herrmann, M. J., and Reif, A. (2013). The effect of emotional content on brain activation and the late positive potential in a word n-back task. PLoS ONE 8:e75598. doi: 10.1371/journal.pone.0075598

Marx, I., Domes, G., Havenstein, C., Berger, C., Schulze, L., and Herpertz, S. C. (2011). Enhanced emotional interference on working memory 
performance in adults with ADHD. World J. Biol. Psychiatry 12, 70-75. doi: 10.3109/15622975.2011.599213

Meule, A. (2016). Dieting and food cue-related working memory performance. Front. Psychol. 7:1944. doi: 10.3389/fpsyg.2016.01944

Meule, A., Skirde, A. K., Freund, R., Vögele, C., and Kübler, A. (2012). High-calorie food-cues impair working memory performance in high and low food cravers. Appetite 59, 264-269. doi: 10.1016/j.appet.2012.05.010

Miller, K. M., Price, C. C., Okun, M. S., Montijo, H., and Bowers, D. (2009). Is the n-back task a valid neuropsychological measure for assessing working memory? Arch. Clin. Neuropsychol. 24, 711-717. doi: 10.1093/arclin/acp063

Newman, J. P., Widom, C. S., and Nathan, S. (1985). Passive avoidance in syndromes of disinhibition: psychopathy and extraversion. J. Pers. Soc. Psychol. 48, 1316-1327. doi: 10.1037/0022-3514.48.5.1316

Oberauer, K. (2005). Binding and inhibition in working memory: individual and age differences in short-term recognition. J. Exp. Psychol. Gen. 134, 368-387. doi: 10.1037/0096-3445.134.3.368

Owen, A. M., McMillan, K. M., Laird, A. R., and Bullmore, E. (2005). Nback working memory paradigm: a meta-analysis of normative functional neuroimaging. Hum. Brain Mapp. 25, 46-59. doi: 10.1002/hbm.20131
Perlstein, W. M., Dixit, N. K., Carter, C. S., Noll, D. C., and Cohen, J. D. (2003). Prefrontal cortex dysfunction mediates deficits in working memory and prepotent responding in schizophrenia. Biol. Psychiatry 53, 25-38. doi: 10.1016/S0006-3223(02)01675-X

Schmidt, H., Jogia, J., Fast, K., Christodoulou, T., Haldane, M., Kumari, V., et al. (2009). No gender differences in brain activation during the N-back task: an fMRI study in healthy individuals. Hum. Brain Mapp. 30, 3609-3615. doi: 10.1002/hbm.20783

Conflict of Interest Statement: The author declares that the research was conducted in the absence of any commercial or financial relationships that could be construed as a potential conflict of interest.

Copyright $\odot 2017$ Meule. This is an open-access article distributed under the terms of the Creative Commons Attribution License (CC BY). The use, distribution or reproduction in other forums is permitted, provided the original author(s) or licensor are credited and that the original publication in this journal is cited, in accordance with accepted academic practice. No use, distribution or reproduction is permitted which does not comply with these terms. 